\title{
A Case of Unusual Anatomy in Second Mandibular Molar with Four Canals
}

\author{
C. Maniglia-Ferreira \\ Fábio de Almeida-Gomes ${ }^{a, b}$ \\ Bruno Carvalho de Sousab \\ Carla Cabral dos Santos Acioli Lins ${ }^{b}$ \\ Roberto Alves dos Santos ${ }^{c}$
}

\section{ABSTRACT}

Success in root canal treatment is achieved after thought cleaning and shaping followed by the complete obturation of root canal system. Such treatment may be performed in root canal systems that do not comply with the normal anatomical features described in standard textbooks. This article describes the conventional root canal treatment on an unusual mandibular second molar with four root-canals. (Eur J Dent 2008;2:217-219)

Key words: Anatomy; Endodontics; Root canal filling; Root canal system.

\section{INTRODUCTION}

Consistently high levels of success in endodontic treatment require an understanding of root canal anatomy and morphology. To achieve endodontic success, the entire root canal system must be adequately debrided and filled. The clinician must have a thorough understanding of normal anatomy and of common variations from the norm. The clinician must also be prepared to identify those teeth that exhibit unusual anatomical configurations. ${ }^{1}$

Cleaning and shaping root canal systems are

- Assistant professor, Department of Endodontics, University of Fortaleza, CE, Brazil.

b Graduate student, PhD program, Department of Endodontics, University of Pernambuco, Brazil.

Adjunct professor, Department of Endodontics, University of Pernambuco, Brazil.

- Corresponding author: Fábio de Almeida-Gomes Rua Arquiteto Reginaldo Rangel 155, ap.1403,

Parque do Cocó, Fortaleza, Ceará, Brazil, CEP:60191-250.

E-mail: fabiogomescedyahoo.com.br essential steps in root-canal treatment. ${ }^{2}$ The goal of root canal treatment is to clean the root canal systems as thoroughly as possible and to fill it in all its dimensions. ${ }^{3}$ In depth knowledge of the root canal anatomy of each tooth is crucial in order to reach this goal. ${ }^{4-6}$ Thus, it is necessary for the clinician to have knowledge of dental anatomy and its variations. ${ }^{7}$

According to Vertucci, ${ }^{8}$ the mandibular second molar is similar to the first, except that the roots are shorter, the canals more curved, and the range of the variations broader. Very often (64\%) the mesial root has two canals, approximately $38 \%$ incidence for type $\mathrm{II}$ and $26 \%$ incidence for type IV. In the distal root, there is almost always only one independent canal (92\%) (type I), rarely type II (3\%) or type IV ( $4 \%)$. When type I is a single canal extends from the pulp chamber to the apex; type II are two separate canals leave the pulp chamber and join short of the apex to form one canal and the type IV are two separate and 
distinct canals extend from the pulp chamber to the apex. The purpose of this clinical report is to describe an anatomic abnormality that was detected during routine root canal treatment in a mandibular second molar.

\section{CASE REPORT}

A 54 year-old female was referred for rootcanal treatment of her right mandibular second molar. The clinical diagnosis was necrotic pulp with apical lesion (Figure 1).

A pre-treatment radiograph was taken, and

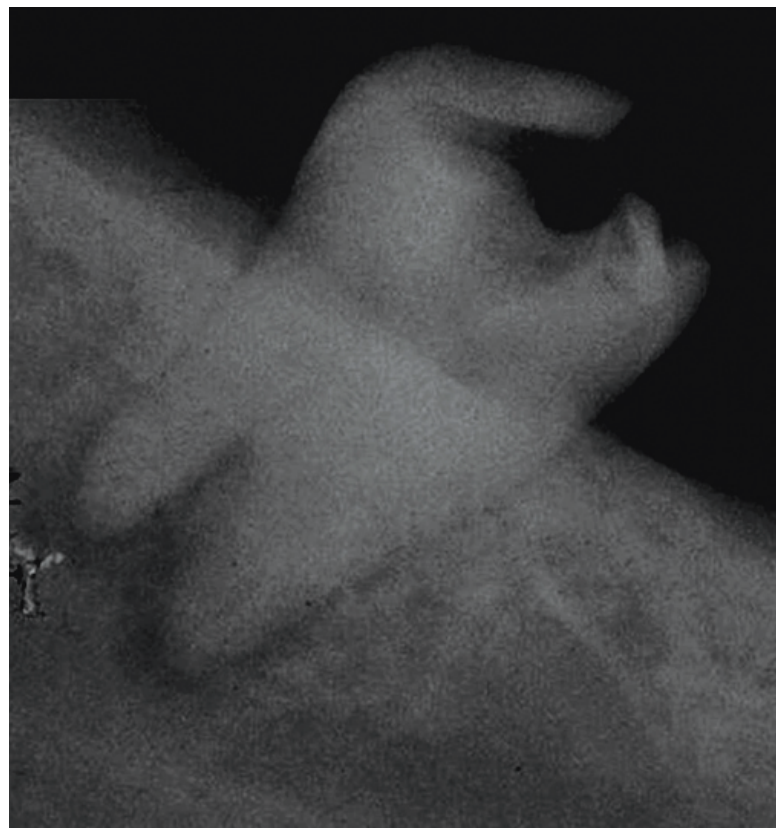

Figure 1. Preoperative radiograph of the right mandibular second molar.

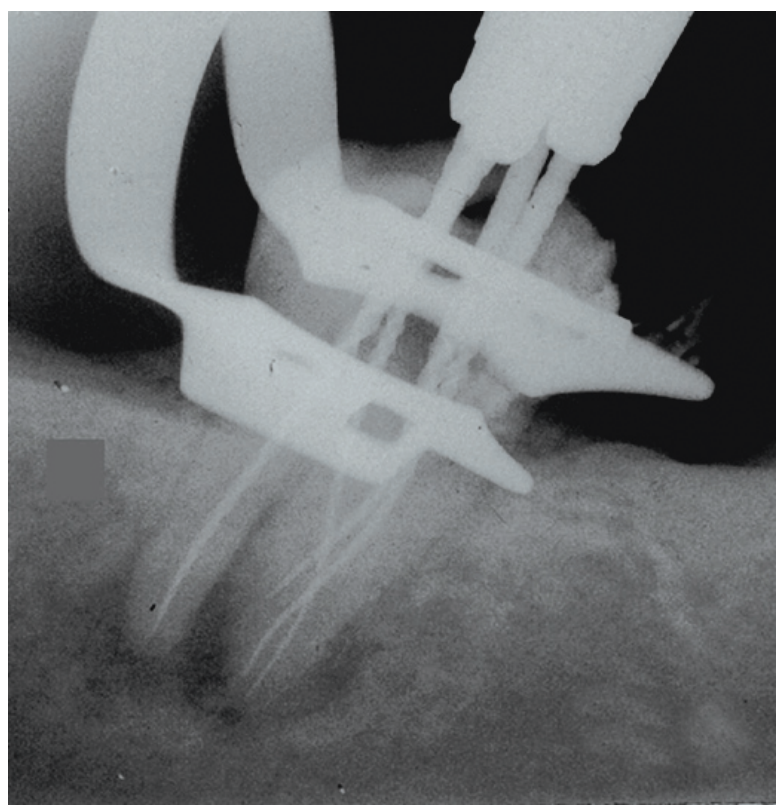

Figure 3. Radiograph with the instruments placed in their positions. after placing a rubber dam, conventional coronal access was performed. After removing tissue located in the pulp chamber, four orifices was observed, two mesial and two distal (Figure 2). Sodium Hypochlorite (4.5\%) and EDTA (17\%) solutions were used as endodontic irrigant. Cleaning and shaping was initiated using the crown-down technique with Gates-Glidden drills (Dentsply-Maillefer, Ballaigues, Switzerland) numbers 2-5 at the cervical and middle-thirds of the root canals. The manual instrument size 15 was used to apical patency.

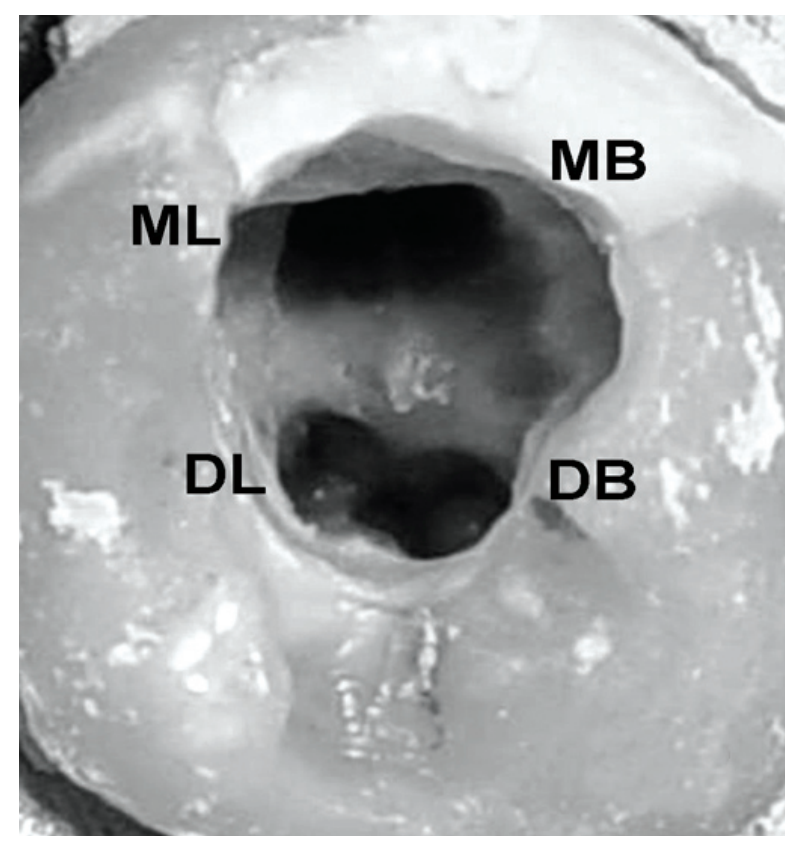

Figure 2. Clinical view of pulp chamber after cleaning and shaping.

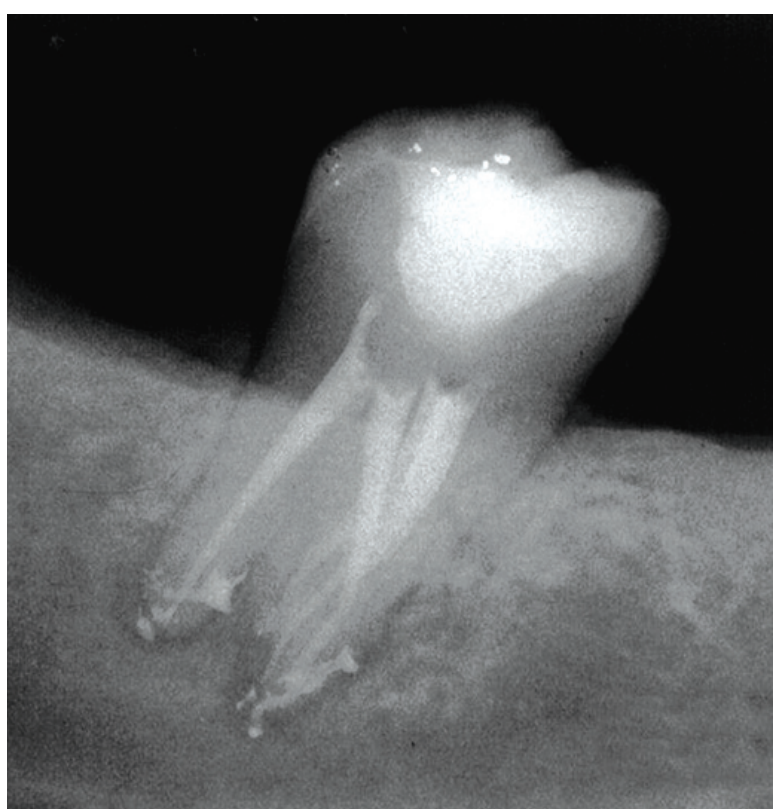

Figure 4. Postoperative radiograph demonstrating the presence of root canal system. 
The canal was negotiated to the working length, as indicated by an apex locator (Root ZX, J. Morita MFG Corp, Kyoto, Japan), with a stainless steel size 15 hand file. During root canal length confirmation by X-ray image (Figure 3) it was noted that the distolingual orifice was the access of the third mesial root canal. Apical preparation was performed by using ProFile (Tulsa Dental Products, Tulsa, USA). The master apical file was size \#30 for all the root canals. Obturation of root canal system was performed by wave of condensation technique and Tagger's Technique was used for the backfilling, using gutta-percha points (Konne, Belo Horizonte, Brazil) and Pulp Canal Sealer (Kerr Corporation, Orange, USA) (Figure 4). Periapical repair was observed 13 months postoperatively (Figure 5).

\section{DISCUSSION}

When anatomic variations are detected clinically, treatment can be performed with conventional or rotary instrumentation an root canal system filling techniques respecting technical and biological principles. The use of apex locator can be important to determine the working length. Additional anatomic information about the root canals can be obtained by careful observation of the positioning and deformation of instruments. ${ }^{9}$

Endodontic success in teeth with a number and morphology of canals above that normally found

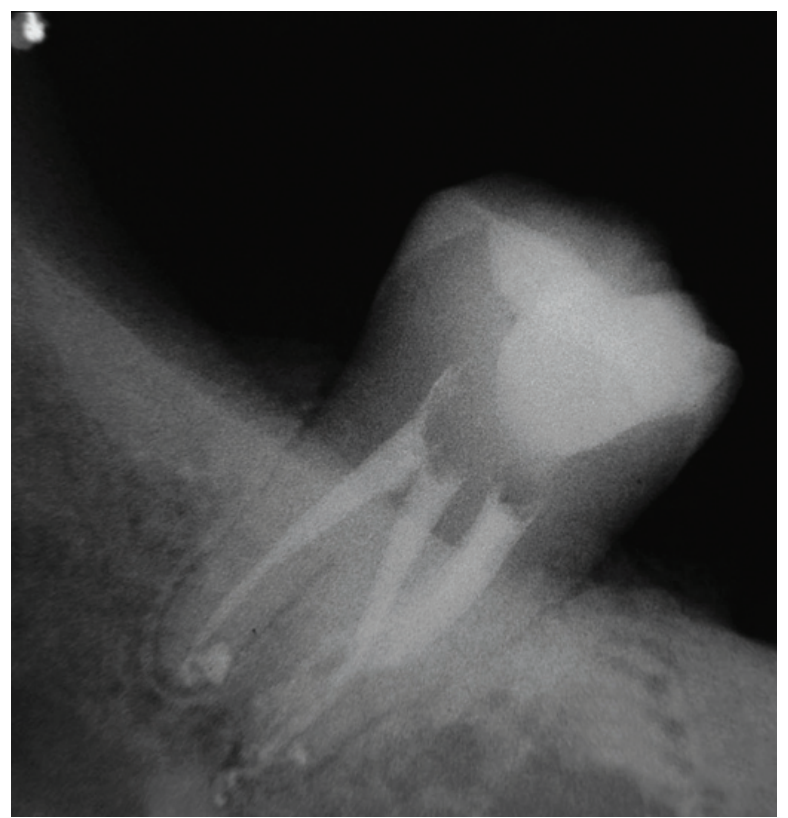

Figure 5. Periapical repair observed 13 months postoperatively. requires a correct diagnosis and careful clinical radiographic inspection. Morphological variations in pulpal anatomy must be always considered beginning treatment. The case presented show that an abnormal anatomic configuration of mandibular molar root canal. The case presents a mandibular second molar with four canals and the distolingual orifice was the access of the third mesial root canal.

\section{CONCLUSIONS}

When root canal treatment is to be performed the clinician should be aware that both external and internal anatomy may be abnormal. Knowledge of possible variations in internal anatomy of human teeth is important for successful endodontic treatment. Root canal treatment was carried out successfully and the prognosis should be good.

\section{REFERENCES}

1. Nallapati S. Three canal mandibular first and second premolars: a treatment approach. A case report. $J$ Endod 2005;31:474-476.

2. Byström A, Sundqvist G. Bacteriologic evaluation of the effect of 0,5 percent sodium hypochlorite in endodontic therapy. Oral Surg Oral Med Oral Pathol 1983;55:307-312.

3. Cohen S, Burns RC. Pathways of the pulp. St Louis: Missouri: 2002. 8th edn.: Mosby CO.

4. Maggiore F, Jou YT, Kim S. A six-canal maxillary first molar: case report. Int Endod J 2002;35:486-491.

5. Almeida-Gomes F, Sousa BC, Santos RA. Unusual anatomy of mandibular premolars. Aust Endod J 2006;32:43-45.

6. Ferreira CM, Moraes IG, Bernardineli N. Three-rooted maxillary second premolar. J Endod 2000;26:105-106.

7. Baratto-Filho F, Fariniuk LF, Ferreira EL, Pecora JD, CruzFilho AM, Souza-Neto MD. Clinical and macroscopic study of maxillary molars with two palatal roots. Int Endod $J$ 2002;35:796-801.

8. Vertucci FJ. Root canal anatomy of the human permanent teeth. Oral Surg Oral Med Oral Pathol 1984;58:589-599.

9. Jerome CE, Hanlon RJ Jr. Identifying multiplanar root canal curvatures using stainless-steel instruments. $J$ Endod 2003;29:356-358. 